\title{
Sobre Paisanos itinerantes. Orden estatal y experiencia subalterna en Buenos Aires durante la era de Rosas
}

Buenos Aires: Prometeo, 2018

Judith Farberman

Centro de Estudios de Historia, Cultura y Memoria (CEHCME), Universidad Nacional de Quilmes; Universidad de Buenos Aires; Consejo Nacional de Investigaciones Científicas y Técnicas, Argentina jfarberman@gmail.com

Ensayo recibido: 06 de marzo de 2019. Aprobación final: 16 de julio de 2019.

\section{Resumen}

Ensayo analítico sobre el libro de Ricardo Salvatore (2018) Paisanos itinerantes. Orden estatal y experiencia subalterna en Buenos Aires durante la era de Rosas. Buenos Aires: Prometeo. Se realiza un análisis integral de la obra, en el que se remarcan sus aportes, las discusiones en las que se inserta y se debate acerca de sus hipótesis y resultados.

Palabras Clave: Rosas; Sectores subalternos; Trabajadores rurales

About Paisanos itinerantes. Orden estatal y experiencia subalterna en Buenos Aires durante la era de Rosas

\begin{abstract}
Analytical essay on Ricardo Salvatore's book Paisanos itinerantes. Orden estatal y experiencia subalterna en Buenos Aires durante la era de Rosas (Buenos Aires: Prometeo, 2018). We develop an integral analysis of the work, highlighting its contributions and debating about its hypotheses and results.
\end{abstract}

Keywords: Rosas; subaltern sectors; rural workers

El monumental libro de Ricardo Salvatore comparte con la historiografía actual sobre rosismo algunas premisas -la combinación de coerción y consenso como clave de permanencia del régimen, y la construcción de un vínculo peculiar y paradojal entre Rosas y los sectores subalternos rurales- y agrega también aportes 
de la exclusiva cosecha del autor. A mi juicio, la originalidad del libro no reside tanto en el destierro de los tres mitos que se enuncian en la introducción -las tesis feudales, la idea de Rosas como representante de la clase terrateniente y la "democracia salvaje"- porque hace tiempo que estos habían sido desacreditados por la historiografía. Tampoco descansa en el enfoque subalternista: indudablemente el texto que le debe más a la historiografía agraria argentina de los últimos treinta años. El gran valor del libro, en cambio, es el intento de analizar y problematizar la relación entre los paisanos, el mercado y el estado en los años de Rosas, localizando a sus agentes en ámbitos e interacciones diversas.

Me permito detenerme un momento en cada uno de estos vértices del triángulo. En uno se encuentran los "paisanos itinerantes", generalmente etiquetados como "clase de peón de campo", muy a menudo migrantes del interior desprovistos de redes locales o con redes locales frágiles. Sujetos vulnerables, pero que han aprendido en su obligada experiencia militar la retórica federal y abrigado una expectativa de los derechos. En otro vértice, el mercado, mercado de consumo y de mano de obra, complicado este último por la competencia de las levas militares y la extinción gradual de la esclavitud. Y en el tercer vértice, el estado provincial. Que no es una abstracción, es el ubicuo Rosas y sobre todo sus agentes judiciales de primera instancia. Los jueces de paz y el personal subordinado de alcaldes y tenientes alcaldes son, en efecto, actores protagónicos e interlocutores de los paisanos. Ellos los “construyen" en sus registros, los clasifican, les exigen libretas de conchabo y pasaportes, los apresan y reclutan para el ejército. Como sostuvo Jorge Gelman (2000) hace ya muchos años, estos jueces de paz -jueces legos- no están separados de la sociedad: son la sociedad misma y expresan el sentido común de los vecinos.

Ricardo Salvatore mira este conjunto de relaciones colocándose en el lugar de los paisanos -pero también en los de los jueces de paz-, para observar las interacciones que tienen lugar en los cuarteles, en los mercados, en las estancias y en las fiestas. Se vale de fuentes ampliamente conocidas y de otras mucho menos exploradas, como las filiaciones. Como sabemos, las filiaciones eran una suerte de fichas que las autoridades levantaban al detener e interrogar a los paisanos en sus andanzas. El autor muestra cómo estos registros propiciaron una clasificación de la población -y con ello, la creación de una clase a priori sospechosa de delinquir-. A la vez, cuando hay suerte (para el historiador) y el paisano es elocuente o la autoridad muy curiosa, las filiaciones atesoran voces extremadamente vívidas, capaces de sorprender por los detalles que arrojan sobre los sentimientos, los deseos, las penas y las resistencias de estos sujetos mayoritariamente analfabetos. Son como fragmentos, como astillas de experiencia que configuran un conjunto caleidoscópico al cual el libro trata de encontrarle un sentido. Los relatos que Salvatore, laboriosamente, va reuniendo permiten rehuir de las imágenes sesgadas y estereotipadas de las fuentes más conocidas y asomarnos a la comprensión que del trabajo, de la política, del estado y de la guerra, tenían los paisanos.

Me pregunto si la predilección por las filiaciones, cuya información es desgajada y utilizada en distintos capítulos, puede relacionarse con la poco convencional 
estructura del libro. En efecto, los años rosistas son generalmente abordados a partir de un orden cronológico por la historiografía. Sabemos que no son lo mismo el primer gobierno de Rosas y el interregno de Balcarce y Viamonte, que tiene al Restaurador operando detrás de la escena. La gran crisis del sistema federal desatada por el bloqueo francés y azotada por la política del terror constituye un momento aparte, al igual que el rosismo maduro y rutinizado, funcionando a la manera de una máquina. El caso es que, dejando de lado el último capítulo -que se aventura en el período post Caseros-, el autor prescinde del orden cronológico como estructura. De alguna manera, es como si se sirviera de ese conjunto caleidoscópico que emerge de las filiaciones, de esos fragmentos de experiencia, para organizar las piezas de su puzzle a su manera. Para acompañar a sus paisanos itinerantes, se vale de un formidable registro estatal que no existe antes de Rosas, ni existirá después de él.

Las puntas de análisis que ofrece el texto son innumerables. Para esta breve reseña elijo detenerme, muy velozmente, en tres de ellas -campesinos y mercado, movilidad y clase e identidad política- para hacerlas dialogar con la historiografía existente, señalando lo que me parece más novedoso.

\section{Campesinos y mercado}

¿Cómo se plantan estos campesinos frente a los mercados de trabajo y de bienes? Respecto de la primera cuestión, ya sabíamos que, para retener a los trabajadores en un contexto de penuria por la mano de obra, los estancieros no podían rehuir a los mecanismos de mercado. Hasta el mismo Rosas -mostraba Jorge Gelmanhabía fracasado intentando imponer sistemas coactivos en sus propias estancias (Gelman, 1999). Sabíamos también del poder de negociación de los paisanos, que venía desde antiguo y que seguramente se acrecentó con la expansión de la gran estancia y la continuidad de las levas. Paisanos itinerantes, empero, nos presenta a unos paisanos más modernos y liberales -demasiado liberales, quizás- que la literatura anterior. La movilidad misma de estos sujetos, en un contexto de control de desertores y "vagos" y de persecución política, fortalece esta idea. Movilidad que a menudo implica distancias enormes -tan enormes como las que separan las provincias de arriba de las estancias pampeanas-, que sólo acortan las apretadas redes relacionales, que incluyen parientes, patrones y conocidos, tejidas en varias décadas de migraciones. Los paisanos son modernos porque denuncian el maltrato, exigen el respeto de sus derechos y, más frecuentemente, abandonan al estanciero que les disgusta para intentar un conchabo más conveniente.

La modernidad se revela también en el comportamiento de los sujetos como vendedores y consumidores. Salvatore nos presenta un mercado muy abierto, del que participan productores grandes y pequeños, en el que los paisanos ven cómo los precios se forman ante sus ojos, regatean y atacan, aunque no tengan éxito, el monopolio. Son parte activa de esta economía popular, que también promueve Rosas para su propia conveniencia. Particularmente interesante es el tratamiento 
detallado del consumo de ropa. Ropa para agradar, para regalar, para disfrazarse y escapar de la leva. Ropa que combina uniformes incompletos, y que tiene pretensiones de estar a la moda. Si algo importante y original nos muestra este libro es que, incluso en un régimen que buscaba la homogeneidad cromática y de estilo, ropa y uniformes hacían a la distinción y eventualmente al salvataje de los paisanos.

\section{Movilidad y clase}

De lo dicho hasta ahora, no sorprende que los migrantes del interior tengan un lugar destacado en el libro. ¿Qué diferencia las migraciones de la época rosista de otras más antiguas? Según el autor, los patrones migratorios parecen haber cambiado, en línea con las necesidades del mercado y las amenazas del reclutamiento. La búsqueda de la permanencia y de estadías más largas en Buenos Aires manifestarían estos nuevos patrones y relegarían a un segundo plano los antiguos flujos estacionales en ocasión de las cosechas. Puede, sin embargo, que los viejos migrantes ayuden con sus redes ya arraigadas en ciertos partidos de la campaña, que con su apoyatura habiliten las obstinadas corrientes del siglo XIX. Como sea, los motivos de los flujos migratorios son los mismos de antes, aunque la divergencia entre el tamaño de las economías del interior y la porteña los vuelva más acuciantes: el mercado, el incentivo de un mejor salario, es el poderoso imán que atrae a los santiagueños o cordobeses (Gelman, 2011; Gelman y Santilli, 2011). Las filiaciones que el autor analiza permiten entrever -desafiando la fragmentación política de la Confederación- mundos muy conectados a través de una aceitada circulación de la información. Por eso, esta investigación sobre Buenos Aires resignifica en más de un sentido la historia de las familias del interior: donde la migración es componente estructural de una sociedad, se hace difícil aceptar sin más la preeminencia del patronazgo. Incluso en Santiago del Estero o en Córdoba, donde se lo ha dado por supuesto.

La mirada del estado frente a estos hombres móviles es ambivalente. Desconfía de ellos porque no los conoce; los apresa porque tienen menos espalda sobre la que recostarse y porque, en conjunto, parecen más indiferentes a la causa federal -y aquí hay otra novedad historiográfica-. En todo caso, existe una línea que separa de manera nítida a estos paisanos de sus homónimos más arraigados: mientras sean transeúntes, la vecindad y los derechos que conlleva les serán negados. Como hace muchos años lo señalara Carlos Cansanello (2003), para la época, decir vecino era como decir ciudadano (Cansanello, 2003). Y en este punto, confirma Ricardo Salvatore una intuición suya, ya expresada en otros textos: es entre estos vecinos, en los sectores medios rurales y en los pueblos, donde el rosismo obtiene sus apoyos más sinceros y que más razonablemente pueden explicarse.

¿Quién mejor que el migrante del interior entraba en la "clase de peón de campo"? Aunque el estado valorara a los provincianos como trabajadores, lo cierto es que eran también los más indicados para terminar en el ejército. La contraposición, 
también señalada por la historiografía desde hace tiempo, entre los vecinos milicianos y con derechos y los transeúntes soldados, víctimas del abuso y carne de cañón, viene a cuento en este punto. ${ }^{1}$ En suma, por mucho que la convivencia en los batallones vaya borrando las diferencias regionales y los gustos populares favorezcan la homogeneidad en el vestir, la extensión de la vecindad seguía siendo limitada en tiempos del rosismo.

\section{Identidades federales}

En mis tiempos de estudiante, entendíamos que la división entre unitarios y federales era fundamentalmente facciosa y que sus hombres podían eventualmente intercambiarse. Unitarismo y federalismo remitían también a cierto ideario político o forma de entender la soberanía que en Rosas terminaba por cuajar en un régimen paradojal, que no parecía tener demasiado de federal. Las preguntas no apuntaban a las identidades políticas subalternas porque, en rigor, no era pensable todavía una cultura política de los paisanos.

Creo que fue sobre todo a partir de Los hijos de Facundo, de Ariel de la Fuente (2007), que la popularidad del federalismo empezó a abordarse como una identidad de clase que se solapaba con la política. Al menos quedó claro que este federalismo podía tener un contenido alternativo, incluso más perdurable que el declamado por las elites dirigentes.

Entre tantas paradojas del sistema rosista, Salvatore nos coloca frente a un federalismo que se expresa públicamente en los dichos, en la ropa y en el cumplimiento de la obligación militar. Se valora positivamente a quien pone el cuerpo por la confederación, pero a la vez poner el cuerpo suele ser un castigo que les toca siempre a los mismos. Por tanto, no solamente los unitarios son perseguidos: es la "clase de peón de campo" la que está en la mira del juez de paz. Y los sujetos así encasillados, los sospechosos de siempre, parecen en el libro menos federales -y tiene sus buenas razones- que los paisanos mejor posicionados, los vecinos.

En suma, Paisanos itinerantes nos ofrece una pintura compleja del régimen rosista, que una vez más desnuda sus paradojas y ambigüedades. Un régimen que busca crear un orden propietario, pero intervenido por el estado, y que contiene un cierto sentido redistributivo. Un régimen que exalta a quienes defienden al federalismo por las armas, pero carga siempre a los mismos con las prestaciones militares. Un régimen que es porteño pero a la vez supraprovincial. Un régimen que es desafiado, no sólo por opositores declarados y que lo hacen abiertamente, sino a través de actitudes, gestos y pequeños actos de resistencia. Cabe decir que, en este sentido, la concepción subalterna de la política como paternalismo republicano entra en cierta contradicción con la modernidad y el liberalismo atribuido en otros planos a los paisanos. 


\section{Bibliografía}

"Cansanello, C. (2003). De súbditos a ciudadanos. Ensayo sobre las libertades en los orígenes republicanos Buenos Aires, 1810-1852. Buenos Aires: Imago Mundi.

"De la Fuente, A. (2007). Los hijos de Facundo. Caudillos y montoneras en la provincia de La Rioja durante el proceso de formación del estado nacional argentino (1853-1870). Buenos Aires: Prometeo.

" Garavaglia, J.C. (2003). Ejército y milicia: los campesinos bonaerenses y el peso de las exigencias militares, 1810-1860. Anuario IEHS, 18, pp. 153-187.

" Gelman, J. (1999). El fracaso de los sistemas coactivos del trabajo rural en Buenos Aires bajo el rosismo: algunas explicaciones preliminares. Revista de Indias, 49 (215), pp. 123141.

" Gelman, J. (2000). Crisis y reconstrucción del orden en la campaña de Buenos Aires. Estado y sociedad en la primera mitad del siglo XIX, Boletín del Instituto de Historia Argentina y Americana Dr. E. Ravignani, 21, pp. 7-31.

" Gelman, J. (2011). Introducción. Desequilibrios regionales, desigualdades sociales. En El mapa de la desigualdad en la Argentina del siglo XIX. Rosario: Prohistoria, pp. 11-45

" Gelman, J. y D. Santilli (2011). Crecimiento económico, divergencia regional y distribución de la riqueza. Córdoba y Buenos Aires después de la independencia. En Gelman, J., El mapa de la desigualdad..., pp. 71-93. 